NOTICE: this is the author's version of a work that was accepted for publication in Pain. Changes resulting from the publishing process, such as peer review, editing, corrections, structural formatting, and other quality control mechanisms may not be reflected in this document. Changes may have been made to this work since it was submitted for publication. A definitive version was subsequently published in Pain, Vol. 154, No. 12 (2013). DOI: 10.1016/j.pain.2013.08.018 


\title{
Identification of neuropathic pain in patients with neck/upper limb pain: application of a grading system and screening tools
}

\author{
Authors: Brigitte Tampin ${ }^{1,2,3}$, Noelle Kathryn Briffa ${ }^{1}$, Roger Goucke ${ }^{4}$, Helen Slater ${ }^{1,5}$ \\ ${ }^{1}$ School of Physiotherapy, Curtin Health Innovation Research Institute, Curtin University, \\ Perth, Western Australia \\ ${ }^{2}$ Department of Physiotherapy, Sir Charles Gairdner Hospital, Perth, Western Australia \\ ${ }^{3}$ Department of Neurosurgery, Sir Charles Gairdner Hospital, Perth, Western Australia \\ ${ }^{4}$ Department of Pain Management, Sir Charles Gairdner Hospital, Perth, Western \\ Australia \\ ${ }^{5}$ Pain Medicine Unit, Fremantle Hospital and Health Service, Fremantle, Western \\ Australia
}

Number of text pages of entire manuscript: 52

Number of figures: 2

Number of tables: 5

Author to whom correspondence should be sent:

Brigitte Tampin

School of Physiotherapy

Building 408, Level 3

Curtin University

GPO Box U1987 
Perth, Western Australia 6845, Australia

Tel: +61 892664644

Fax: +61 892663699

Email: bvdh@iinet.net.au; Brigitte.Tampin@health.wa.gov.au

Keywords: Neuropathic pain; clinical assessment, painDETECT, LANSS, pain questionnaire 


\begin{abstract}
The neuropathic pain special interest group (NeuPSIG) of the International Association for the Study of Pain has proposed a grading system for the presence of neuropathic pain (NeP) using the following categories: no NeP, possible, probable or definite NeP. To further evaluate this system we investigated patients with neck/upper limb pain with a suspected nerve lesion, to explore: (i) the clinical application of this grading system; (ii) the suitability of two NeP questionnaires (Leeds Assessment of Neuropathic Symptoms and Signs pain scale (LANSS); painDETECT questionnaire (PD-Q)) in identifying $\mathrm{NeP}$ in this patient cohort and; (iii) the level of agreement in identifying $\mathrm{NeP}$ between the NeuPSIG classification system and two NeP questionnaires. Patients (N=152; age $52 \pm$ 12 years; 53\% male) completed the PD-Q and LANSS questionnaire and underwent a comprehensive clinical examination. The NeuPSIG grading system proved feasible for application in this patient cohort, although required considerable time and expertise. Both questionnaires failed to identify a large number of patients with clinically-classified definite NeP (LANSS sensitivity 22\%, specificity 88\%; PD-Q sensitivity 64\%, specificity $62 \%)$. These lowered sensitivity scores contrast with those from the original PD-Q and LANSS validation studies and may reflect differences in the clinical characteristics of the study populations. The diagnostic accuracy of LANSS and PD-Q for the identification of $\mathrm{NeP}$ in patients with neck/upper limb pain appears limited.
\end{abstract}




\section{Introduction}

Neuropathic pain $(\mathrm{NeP})$, defined as "pain arising as a direct consequence of a lesion or disease affecting the somatosensory system" $[42 ; 64]$ is associated with more severe pain for patients than nociceptive pain $[18 ; 30]$ and with suffering, disability, impaired health-related quality of life $[13 ; 25 ; 30]$, and increased health care cost $[30 ; 60]$. Thus, early identification of $\mathrm{NeP}$ is crucial, as $\mathrm{NeP}$ in particular requires targeted management $[4 ; 38]$. As no "gold standard" exists for the diagnosis of NeP, a grading system with different levels of certainty about the presence of $\mathrm{NeP}$ (no, possible, probable, definite) has been developed by the Neuropathic Pain Special Interest Group (NeuPSIG) of the International Association for the Study of Pain [64]. This classification approach is based on a stepwise process that requires a history-derived working hypothesis (based on pain distribution and history suggesting a relevant lesion), and confirmatory evidence from a neurological examination and diagnostic tests. The application of this grading system has been demonstrated in some case studies [31;35], and was consequently used in various pain populations $[32 ; 39 ; 43]$, but not in patients with neck/upper limb pain.

Questionnaires are used as screening tools to aid identification of suspected $\mathrm{NeP}$ $[10 ; 22]$ and are recommended for clinical use, including by non-specialists [34]. The Leeds Assessment of Neuropathic Symptoms and Signs pain scale (LANSS)[9] discriminates between patients with or without pain of predominantly neuropathic origin, and is applied in an interview format. The LANSS contains five sensory descriptor items and two clinical examination items. LANSS was developed in 60 patients with distinct clinical diagnostic categories of $\mathrm{NeP}$ and non-NeP, and 
demonstrated a sensitivity of $83 \%$ and specificity of $87 \%$, and was further validated in 40 patients (sensitivity $85 \%$, specificity of $80 \%$ ) [9].

The painDETECT questionnaire (PD-Q) [30] is another NeP screening tool, with the additional concept of grading for the certainty of the presence of NeP. PD-Q classifies patients into three groups: a NeP component is unlikely, results are ambiguous, or a NeP component is likely. The questionnaire is a self-administered tool consisting of seven weighted sensory descriptors, plus one item relating to spatial pain characteristics and one relating to temporal characteristics. PD-Q was developed and validated in 392 German patients with clinically diagnosed pain of predominantly either nociceptive or neuropathic origin and demonstrated a sensitivity of $85 \%$ and specificity of $80 \%$.

LANSS and PD-Q appear to demonstrate the same level of diagnostic accuracy in identifying NeP. However, it is unclear if they have similar performances when applied to a single patient cohort presenting with mixed musculoskeletal and peripheral $\mathrm{NeP}$. If this were the case, the use of PD-Q would be preferable in primary care, as it would save valuable practitioner time.

The aims of this study were to investigate:

(i) the clinical application of the NeuPSIG grading system in patients with neck/upper limb pain;

(ii) the suitability of LANSS and PD-Q as tools for the accurate identification of NeP in these patients 
(iii) the level of agreement in detecting $\mathrm{NeP}$ between the NeuPSIG classification system and the LANSS and PD-Q. 


\section{Materials and methods}

\subsection{Study population}

The study (prospective) was conducted between June 2008 and December 2009 inclusive. Patients with neck/upper limb pain and suspected nerve lesion were recruited from an outpatient neurosurgery triage clinic in a large metropolitan hospital. Patients had been referred to this clinic by their general practitioner or from other departments within the hospital. The study was registered with the Quality Improvement Unit of Sir Charles Gairdner Hospital (registration number 2109) and endorsed by the Hospital's Human Research Ethics Committee.

\subsection{Clinical examination}

All study patients were examined by a clinician with a postgraduate Masters qualification in musculoskeletal physiotherapy and who specialised in triaging patients with musculoskeletal and neuropathic pain disorders in a tertiary neurosurgical setting (BT). The clinician was not blinded to the patient referral, however a referral may not have contained a diagnosis as often the patient's symptoms rather than a diagnosis were described, i.e. neck pain with tingling in the hand. The clinical assessment comprised of taking the patient's history, pain drawings including location and intensity of pain, documentation of pain descriptors and pain behaviours, musculoskeletal assessments and neurological examination. Sensory testing of light touch and pin-prick sensation was performed in the most painful area [34] and compared with findings in the contralateral corresponding control site. In patients with bilateral pain, proximal or distal pain-free sites were used for control testing $[34 ; 35 ; 41]$. Thermal testing was not performed in this study, consistent with previously documented methodology $[9 ; 17 ; 39 ; 66]$. Pin-prick thresholds can give 
comparable information on the function of unmyelinated C-fibers as a strong correlation between pin-prick and thermal thresholds has been shown [20]. Furthermore it has been commented that the assessment of thermal sensitivity is considered less practical due to the requirement for special equipment [17]. Patients were asked to report the stimulus intensity (normal, less = hypoaesthesia; more $=$ hyperaesthesia) and quality (normal or other = paraesthesia, dysaesthesia, allodynia) compared to the control site. Sensory testing was also performed in both upper limbs for determination of dermatomal sensory deficits and in both lower limbs, if spinal cord compromise was suspected. Finally, available results from any other investigations (i.e. imaging, nerve conduction studies (NCS)) were reviewed to identify any evidence of a lesion/disease of the somatosensory system. Based on all the above findings patients' pain conditions were categorised by the one clinician according to the NeuPSIG classification system, using a hierarchical order, into either no NeP, possible, probable or definite NeP. As some patients presented with multiple pain areas, the classification for $\mathrm{NeP}$ was applied to the patient's maximal pain area.

The classification system comprises the following four criteria [64]:

1. Pain with a distinct neuroanatomically plausible distribution

2. A history suggestive of a relevant lesion or disease affecting the peripheral or central somatosensory system

3. Demonstration of the distinct neuroanatomically plausible distribution by at least one confirmatory test (presence of negative or positive sensory signs concordant with the distribution of pain)

4. Demonstration of the relevant lesion or disease by at least one confirmatory test (e.g. neuroimaging, neurophysiological methods) 
Definite $\mathrm{NeP}$ is defined by the presence of all 4 criteria; probable $\mathrm{NeP}$ is defined by the presence of Criteria 1 and 2, plus either 3 or 4 and possible $\mathrm{NeP}$ by the presence of Criteria 1 and 2, without confirmatory evidence from 3 or 4 [64]. With respect to Criterion 3 , in our study only sensory abnormalities in the main pain area were classified as a confirmatory response. If no abnormalities were found in the main pain area, but sensory changes existed in further distal areas (e.g. distal dermatomal sensory changes in patients with cervical radiculopathy), this was classified as not fulfilling Criterion 3. If imaging results were used for radiological confirmation of nerve compression, only radiologist's reports indicating significant/severe cervical foraminal stenosis and compromise of the exiting nerve root at the clinically relevant level were deemed as a confirmatory test. If the report stated "mild to moderate foraminal narrowing" with no mention of nerve root compromise, this was classified as a non-confirmatory test. The radiologist's grading of nerve root compromise was based on standard radiology reporting procedures as defined by an experienced neuroradiologist.

While some studies used the consensus of two clinicians for validation of patient classification, others have used only a single clinical judgement $[9 ; 11 ; 24 ; 36 ; 39 ; 66]$. Our approach is consistent with the latter and was chosen as we encountered the problem of time and resource limitations required for patient assessment by two examiners. Furthermore, repeated assessment would have imposed a considerable burden on the patients and could potentially cause an exacerbation of the patients' condition, raising ethical concerns. 


\subsection{Questionnaires}

The LANSS was chosen for this project as it has been documented in several studies to be a reliable and valid tool for the identification of $\mathrm{NeP}[9 ; 54 ; 65 ; 68]$, including the identification of $\mathrm{NeP}$ in patients with cervical or lumbar radiculopathy $[9 ; 54 ; 65 ; 68]$. The PD-Q is a much more recent tool, is easy to implement in clinical practice, is available in English and has been applied in English speaking populations [7;29;33]. In contrast to all other NeP screening tools [10], PD-Q was designed for identifying NeP components specifically in low back pain patients with and without referred pain. The PD-Q as well as LANSS might be transferable to neck pain conditions with and without referred pain and therefore seemed appropriate to be used for our patient cohort.

All participants completed the PD-Q prior to clinical examination whilst they were in the waiting room. No specific instructions were given to patients on how to complete the questionnaire, consistent with the PD-Q format. The questionnaire asks patients to mark their main pain area on a body chart. The weighted sensory item descriptors relate to this marked main pain area. A PD-Q score of $\leq 12$ indicates that a NeP component is unlikely, and a score of $\geq 19$ indicates a likely presence of a $\mathrm{NeP}$ component [30]. Scores between 13 and 18 reflect an ambiguous result. The clinician was blinded to the PD-Q responses. The LANSS was administered unblinded in an interview format at the end of the clinical examination. The required testing for the LANSS (testing for allodynia with cotton wool, altered pin-prick threshold with 23 gauge needle) was performed during the overall neurological bedside examination. A score of $<12$ indicates that neuropathic components are unlikely to contribute to the

patient's pain and a score of $\geq 12$ suggests that $\mathrm{NeP}$ components are likely to be 
contributing to the pain presentation. In addition, the strongest and average pain intensity over the last four weeks and pain intensity at the time of the assessment were documented on a numeric rating scale (NRS) as part of the PD-Q $(0=$ no pain, $10=$ maximum pain). 


\subsection{Statistical analysis}

Data were analysed using the Statistical Package for Social Sciences (SPSS Version 17.0). One-way ANOVA and Kruskal-Wallis test were used to compare patient characteristics between pain classification groups (no, possible, probable, and definite NeP). Frequencies of pain descriptors were calculated. A pair-wise comparison was performed between:

- clinical classification and LANSS;

- clinical classification and PD-Q;

- LANSS and PD-Q.

The Kappa coefficient and 95\% confidence intervals were calculated for all comparisons as well as the percentage of agreement [46]. As the LANSS uses a dichotomous scale, PD-Q and the clinical classification score were transformed into dichotomous variables: PD-Q scores $<19$ were defined as no $\mathrm{NeP}$ and $\geq 19$ as $\mathrm{NeP}$. For the clinical classification, no, possible and probable $\mathrm{NeP}$ were all grouped as no NeP. Sensitivity and specificity were calculated for the LANSS and PD-Q, using the clinical classification as the "gold standard" [56]. Sensitivity was calculated by dividing the true positives by the sum of true positives and false negatives [56]. Specificity was calculated by dividing the true negatives by the sum of true negatives and false positives. Predictive values (positive and negative predictive values, likelihood ratios, diagnostic odds ratios) were also calculated. The receiver operating characteristic (ROC) curves were graphed and the areas under the curve (AUC) plus their $95 \%$ confidence intervals were calculated for each questionnaire. The ROC curve analysis was used to determine the cut-off score for the questionnaires used. Logistic regression analysis was performed to examine the utility of each item descriptor of the LANSS and PD-Q to discriminate NeP. For the latter analysis, the 
seven item descriptors of the PD-Q which have five possible scores (never $=0$; hardly noticed $=1$; slightly $=2$; moderately $=3$; strongly $=4$; very strongly $=5$ ) were transformed into dichotomous variables. Scores $\geq 3$ were defined as a positive response and scores of $<3$ as a negative response, consistent with previous methodology [62].

Furthermore, given the concept of grading the certainty of the presence of $\mathrm{NeP}$ in both the clinical classification system and PD-Q, an analysis was performed to compare the agreement in classifying patients as having $\mathrm{NeP}$, no $\mathrm{NeP}$ and unclear/ambiguous classification. To investigate whether the questionnaires were able to identify patients who were clinically classified as having probable $\mathrm{NeP}$, consistent with other studies [32;43;65], three categories per classification were defined as follows: LANSS (scores $0-8=$ no NeP [12], $9-11$ unclear, $12-24 \mathrm{NeP}$ ), PD-Q (scores $0-12=$ no $\mathrm{NeP}, 13-18=$ unclear, $19-38=\mathrm{NeP}$ ) and clinical classification (no NeP, possible as unclear cases, and probable and definite combined as NeP). The Kappa coefficient and $95 \%$ confidence intervals were calculated for all comparisons, as well as the percentage of agreement. Other data are presented as mean (SD) unless otherwise indicated. Significance was accepted at $\mathrm{p}<0.05$ for all analyses. 


\section{Results}

One hundred and sixty six patients with neck/upper limb pain attended the neurosurgery triage clinic, and of these, 13 did not experience any pain or only paraesthesia at the time of assessment. One patient was excluded from data analysis due to errors in completing the PD-Q, so analyses were performed on 152 patients.

\subsection{Patient characteristics}

The patients' characteristics are shown in Table 1. No listed characteristic was significantly different between the pain classification groups. Patients more likely to have $\mathrm{NeP}$ demonstrated a tendency to higher maximal pain scores during the preceding 4 weeks. A wide spectrum of pain diagnoses/pain presentations was represented (Table 2). Ninety-five patients (62.5\%) presented with conditions likely to include $\mathrm{NeP}$ (radiculopathy, radicular pain, cervical myelopathy and carpal tunnel syndrome) and 57 patients (37.5\%) with predominantly musculoskeletal/nociceptive conditions. Clinical presentations ranged from the presence of a single pain area to multiple causally related pain areas (e.g. neck pain with referred or projected arm pain and paraesthesia) or multiple independent areas (e.g. neck/arm pain with signs of carpal tunnel syndrome). Twenty-four patients experienced bilateral symptoms. Apart from the pain presentations shown in Table 2, 24 patients presented with additional pain areas, which were independent of their main pain area/main complaint (low back pain (LBP) $n=11$, LBP with leg pain $n=4$, leg pain $n=3$, shoulder pain $n=5$, wrist pain $\mathrm{n}=1$ ). Seventy patients had various co-morbidities such as diabetes, thyroid dysfunction, hepatitis $\mathrm{B}$ and $\mathrm{C}$, heart and lung disease, migraine, irritable bowel syndrome, cancer, polymyalgia rheumatica, Parkinson's disease, transient ischemic 
attack, gout, fibromyalgia, epilepsy, brain aneurysm and depression and anxiety disorders.

\subsection{Clinical classification of NeP based on the NeuPSIG system}

The assessment of each patient required on average a 45 minutes consultation. Fifteen patients were classified as no $\mathrm{NeP}, 27$ as possible $\mathrm{NeP}, 65$ as probable $\mathrm{NeP}$ and 45 as definite NeP (Table 2).

\section{Criterion 1}

Fifteen patients were classified as having no $\mathrm{NeP}$ as their pain distribution was not in a distinct neuroanatomically plausible distribution.

\section{Criterion 2}

Seventy patients with spinal pain could not recall a specific onset of their pain, therefore it was not possible to establish an exact temporal link between history and pain distribution. An insidious onset is common for the development of pain associated with spinal degenerative changes [59] and it was determined that these cases therefore satisfied Criterion 2.

\section{Criterion 3}

Sensory abnormalities in the main area of pain were demonstrated in 41 out of the 65 patients classified as having probable $\mathrm{NeP}$ and in all patients with definite NeP. Fiftytwo patients presented with more than one sensory abnormality (no $\mathrm{NeP}, \mathrm{n}=1$; possible $\mathrm{NeP}, \mathrm{n}=0$; probable $\mathrm{NeP}, \mathrm{n}=24$; definite $\mathrm{NeP}, \mathrm{n}=27$ ). Five patients

demonstrated allodynia. The presence of hyposensitivity to one or several modalities 
(light touch, pin-prick) $(n=44)$ was more common than hyperaesthesia $(n=31)$. Ten patients presented with mixed hypo- and hypersensitivities.

Seven patients classified as having probable NeP, and three patients with possible $\mathrm{NeP}$, did not have any sensory abnormalities in their main pain area. However, all these patients demonstrated sensory deficits in a distal dermatomal distribution, and this combined with the clinical history supported the likely presence of a nerve lesion. According to our interpretation these cases did not satisfy Criterion 3. In three patients with probable $\mathrm{NeP}$, no sensory abnormalities were found in the main area of pain, but sensory abnormalities were present in a distal, non-dermatomal distribution, and were not causally related to the main area of pain. These cases were also interpreted as not fulfilling Criterion 3. For two patients, sensory abnormalities were not recorded in the area of maximal pain (neck pain), but in a projected pain area (arm), and this was interpreted as a confirmatory test for Criterion 3 [45]. In 24 patients classified as probable NeP, no sensory abnormalities were found in the main pain area or in distal dermatomal areas, but confirmatory tests of nerve compression were available to determine the classification of probable NeP (NCS: $n=1$; surgery: $n$ $=1$; Computerised Tomography $(\mathrm{CT})$ or Magnetic Resonance Imaging $(\mathrm{MRI}): \mathrm{n}=$ 22). CT scans and MRI are deemed to be valid confirmatory tests for nerve root compression $[15 ; 64]$.

\section{Criterion 4}

Imaging results of the cervical spine to allow possible radiological confirmation of nerve compression were available for 140 patients (plain radiography $\mathrm{n}=7$; CT $\mathrm{n}=$ 108; MRI $\mathrm{n}=25$ ). Considering the possibility of false positive findings on imaging 
[47;50], we adopted a very conservative approach and defined only radiologist's reports indicating significant/severe cervical foraminal stenosis and compromise of the exiting nerve root at the clinically relevant level as a confirmatory test. Plain radiography was not considered as a confirmatory test. Results of NCS were available for six patients. Of nine patients without any diagnostic tests, three were classified with probable $\mathrm{NeP}$, three with possible and three with no NeP.

\subsection{Volunteered pain descriptors}

The frequency of reported pain descriptors obtained during the clinical examination from patients classified as having no $\mathrm{NeP}$, possible, probable or definite $\mathrm{NeP}$ are shown in Figure 1. The description of electric shock type pain occurred only in the probable and definite NeP groups. Tingling sensations and the presence of sharp pain was most frequently reported in the probable and definite $\mathrm{NeP}$ groups ( $20 \%-28.9 \%)$ and not at all in the no NeP group. Other pain descriptors associated with $\mathrm{NeP}$ (e.g. numb, hot, shooting) were also not used in the no NeP category and occurred infrequently in the probable and definite group (4.4\% - 12.3\%). The descriptors burning and ache were reported in all groups in the following proportions: burning pain $26.7 \%$ in no NeP; $22.2 \%$ in possible NeP; $32.3 \%$ in probable and $35.6 \%$ in definite $\mathrm{NeP}$ respectively; ache $33.3 \%$ in no $\mathrm{NeP}, 11.1 \%$ in possible $\mathrm{NeP}, 24.6 \%$ in probable NeP; and $26.7 \%$ in definite NeP. Spontaneous pain was reported in $41 \%$ of patients during the clinical examination with increased frequency and increased likelihood of $\mathrm{NeP}$ (no NeP, $\mathrm{n}=1$; possible $\mathrm{NeP}, \mathrm{n}=10$; probable $\mathrm{NeP}, \mathrm{n}=26$; definite $\mathrm{NeP}, \mathrm{n}=25)$. 


\subsection{Agreement between clinical classification and questionnaires where patients}

were classified as having $\mathrm{NeP}$ or no $\mathrm{NeP}$

\subsubsection{LANSS and clinical classification of $\mathrm{NeP}$}

Twenty-three patients met the LANSS criteria for predominantly NeP (mean (SD) score $14.3(2.0))$ and 129 for without predominantly NeP (6.0 (3.8)) (Table 3). There was agreement between the LANSS and the clinical classification in 104 of the 152 cases (no NeP: $\mathrm{n}=94, \mathrm{NeP}: \mathrm{n}=10$; Kappa $0.12,95 \%$ CI -.04 to .28) (Table 3), which yielded a $68.4 \%$ agreement. Using the clinical classification as the "gold standard", LANSS demonstrated a sensitivity of $22 \%$ and specificity of $88 \%$ (Table 4 ). The ROC curve is presented in Figure 2. The AUC for the LANSS was 0.73 (95\% CI .64 to .81 ). The appropriate cut-off score for our patient cohort was 8.5.

Out of 48 discordant cases between LANSS and clinical classification, 16 patients $(33 \%)$ scored very close to the original cut off score of $\geq 12$ (11 patients scored $11 ; 5$ patients scored 10). Twelve patients who were classified as having NeP according to the NeuPSIG model, demonstrated hypoaesthesia to light touch (stroking with cotton wool) in their area of maximal pain. However in the LANSS, only allodynia is scored as a relevant sensory abnormality in response to light touch. If hypoaesthesia was scored as a relevant sensory abnormality for $\mathrm{NeP}$, all these patients would have been identified as having NeP. In this case, the percentage of agreement would increase to $76.3 \%$ and LANSS sensitivity would increase to $48 \%$ and specificity would reduce to $77 \%$. The frequency of positive pain descriptors and their discriminative function to identify NeP are documented in Table 5. The verbal descriptor of tingling sensation (p $=0.001)$ and the physical examination items of the presence of allodynia $(p=0.019)$ 
and altered pin-prick sensation $(\mathrm{p}<0.001)$ were statistically significant

discriminators. Three item descriptors of LANSS (skin discoloration as symptom of possible autonomic nervous system dysfunction, tingling sensation and testing of allodynia) yield the highest score $($ score $=5$ ) that is obtainable for a single question in LANSS. Less than $16 \%$ of patients with clinically classified NeP reported symptoms of possible autonomic nervous system dysfunction and allodynia.

\subsubsection{PD-Q and clinical classification of NeP}

The PD-Q identified 70 patients with a NeP component (mean score 23.2, $\mathrm{SD} \pm 3.7$ ) and 82 cases with no NeP component (mean score 11.7, $\mathrm{SD} \pm 4.4$ ) (Table 3 ). There was agreement between the PD-Q and the clinical classification in 95 cases (no NeP: $\mathrm{n}=66, \mathrm{NeP}: \mathrm{n}=29 ;$ Kappa $0.23,95 \%$ CI .07 to .37 ) (Table 3), yielding $62.5 \%$ agreement with a sensitivity of $64 \%$ and a specificity of $62 \%$ (Table 4 ). Out of the remaining 57 cases, a larger number of patients $(n=41)$ were classified as having NeP with PD-Q compared to the clinical classification, which indicated no NeP. Most of these patients scored highly $(\geq 4)$ on the verbal descriptors for the presence of burning pain, tingling sensation, numbness and sudden pain. The ROC curve is demonstrated in Figure 2. The AUC for the PD-Q was 0.63 (95\% CI .53 to .73) and the appropriate cut-off score for our population was 18.5. The item descriptors of pain pattern $(p=0.035)$, tingling sensation $(p=0.001)$, sudden pain attacks/electric shocks $(p=0.001)$ and numbness $(p=0.023)$ were statistically significant discriminators for the presence of $\mathrm{NeP}$ (Table 5). 


\subsubsection{Agreement between questionnaires in identifying $\mathrm{NeP}$}

There was agreement between LANSS and PD-Q in identifying NeP in 95 of the 152 cases (no NeP: $\mathrm{n}=77, \mathrm{NeP}: \mathrm{n}=18$; Kappa 0.21, 95\% CI .09 to .33) (Table 3), yielding a $62.5 \%$ agreement between questionnaire outcomes. For the discordant 57 cases, a NeP component was demonstrated in only five patients for LANSS, but in 52 patients for PD-Q. Questions in the LANSS refer to how the patient's pain felt over the last week. Seven patients did not experience much pain in the week prior to the assessment, but answered the PD-Q questions in relation to how their pain had felt in the past 4 weeks. This resulted in the PD-Q score indicating NeP.

The PD-Q and LANSS have a number of questions in common. These include the presence of a tingling/prickling sensation and burning sensation, if light touch is painful in the area of pain and if pain can come on suddenly (Table 5). However, when comparing responses to the common questions from the two survey tools, 20 patients answered the questions affirmatively in the PD-Q, resulting in the classification of NeP, but responded in the negative in the LANSS. The main discrepancies related to the presence/absence of burning pain $(n=13)$, sensitivity to light touch $(\mathrm{n}=12)$ and sudden pain $(\mathrm{n}=9)$. In the remaining 25 discordant cases and in five cases scoring positive on the LANSS but negative on PD-Q, discrepancies were found in responses to the above named descriptors in 15 patients. However, had patients answered these questions in PD-Q as answered in LANSS, the final score of PD-Q (NeP or no NeP) would not have changed. In 15 patients all questions were answered equally in both questionnaires, but due to scoring differences the overall outcome differed (PD-Q: 14 NeP, 1 no NeP; LANSS: 2 NeP, 13 no NeP). 
3.6. Agreement between clinical classification and questionnaires where patients were classified as having $\mathrm{NeP}$, no NeP or where the classification is unclear

\subsubsection{LANSS and clinical classification of NeP}

There was agreement between the LANSS and the clinical classification in 38 cases

(no NeP: $\mathrm{n}=14$, unclear: $\mathrm{n}=1$, NeP: $\mathrm{n}=23$; Kappa 0.04, 95\% CI -.01 to .09), which yielded a $25.0 \%$ agreement.

\subsection{2. $P D-Q$ and clinical classification of $N e P$}

There was agreement between the PD-Q and the clinical classification in 77 cases (no NeP: $\mathrm{n}=11$, unclear: $\mathrm{n}=8$, NeP: $\mathrm{n}=58$; Kappa $0.17,95 \% \mathrm{CI} .06$ to .28 ), which yielded a $50.7 \%$ agreement.

\subsubsection{Agreement between questionnaires in identifying $\mathrm{NeP}$}

There was agreement between LANSS and painDETECT in identifying NeP in 67 cases (no NeP: $n=40$, unclear: $n=9$, NeP: $n=18$; Kappa 0.19, 95\% CI 0.09 to .29 ), resulting in $44.1 \%$ agreement between questionnaire outcomes. 


\section{Discussion}

The NeuPSIG's proposed diagnostic grading system [64] was feasible for clinical application in this cohort of neck/arm pain patients with a suspected nerve lesion. LANSS [9] and PD-Q [30] failed to identify a large number of patients with clinically-classified definite and probable NeP. The PD-Q demonstrated a higher sensitivity, but a lower specificity than LANSS.

The NeuPSIG classification system has been recommended for use in primary care [35]. In the current study, the majority of patients were referred by their general practitioner and were therefore representative of a primary care population. The clinical assessment and classification of our cohort necessitated considerable time and specific clinical expertise. Considering an average general practice consultation time of 15 minutes $[14 ; 19]$, health professionals working in primary care may not have time for an appropriate in-depth clinical assessment or have the requisite knowledge and skills to apply this grading system.

In our study, 82 patients (54\%) reported the neck/trapezius/scapula/shoulder area as their main area of pain. These body regions correlate with specific cervical nerve root pain distributions [63], but are also a common area for musculoskeletal pain and referred somatic pain [23]. Mixed nociceptive and NeP mechanisms, which were likely to co-exist in our patient sample, have been acknowledged by numerous authors $[2 ; 3 ; 30 ; 49 ; 64]$. In the context of predominant pain mechanisms, the value of sensory pain descriptors has been previously raised $[4 ; 16]$. The combination of some items can discriminate between non-NeP and NeP groups $[9 ; 11 ; 17 ; 27 ; 44]$, however their relevance and incorporation into the NeuPSIG grading system is debatable 
[6;37;48;64]. In our study, the most dominant volunteered discriminators between the no NeP group and all others were the sensory descriptors electric shock, followed by tingling, sharp and spontaneous pain and numbness, corresponding with discriminant descriptors of PD-Q and LANSS, and hot and shooting. Unlike other studies [9;11;17;27;44], pain descriptors were volunteered, not chosen from a nominated descriptors list, thus lending credence to their presence. The descriptor ache, commonly associated with nociceptive pain $[8 ; 28 ; 49 ; 52 ; 61]$, was reported in our patients with NeP components, consistent with other studies [26;61;67].

For the diagnosis of NeP, sensory abnormalities have to be present "concordant with the distribution of pain" (Criterion 3) [64]. This wording may however be open to different interpretations and this could influence patient classification. 'Concordant' can be defined as: "being in agreement with" [21], allowing for interpretations including "sensory abnormalities have to spatially overlap the area of pain" or "sensory abnormalities are associated with the pain distribution and innervation territory of the affected nervous structure, but they do not necessarily overlap the pain area". For example, distal dermatomal hypoaesthesia, (as seen in radiculopathy), could indicate a lesion of the somatosensory system, but its presence does not necessarily indicate the presence of $\mathrm{NeP}$ in an associated proximal main pain area.

The sensitivity of LANSS and PD-Q was much lower compared to previously reported studies [9;30], and the diagnostic accuracy of both questionnaires diminished further with the classification of patients with $\mathrm{NeP}$ (probable and definite $\mathrm{NeP}$ combined), non-NeP and unclear cases. These discrepancies to previous reports may partly be explained by the differences in clinical characteristics of respective study 
cohorts, and this assumption is supported by the fact that only few of the item descriptors of LANSS and PD-Q were discriminative for identifying NeP. Both questionnaires were validated in specific pain clinic populations with and without $\mathrm{NeP}$, and patients with mixed pain were excluded [9;30]. Such study design can introduce spectrum bias and lead to exaggeration of both sensitivity and specificity [55]. In contrast, our cohort consisted of mixed pain aetiologies (e.g. spinal degenerative conditions, radiculopathy, musculoskeletal).

The presence of mixed pain presentations seems to influence the discriminative ability of LANSS. Whilst LANSS demonstrated high sensitivity $(70 \%$ - 89\%) and specificity $(94.2 \%-96.6 \%)$ in patient groups resembling the cohorts in the validation study [65; 68 ], sensitivity reduced slightly from $85.9 \%$ to $81.8 \%$ with the inclusion of mixed pain presentations in a cohort of 156 patients $(42.9 \% \mathrm{NeP}, 14 \%$ mixed pain) [58]. In a large sample of patients with cancer, which was labelled as having a mixed pain mechanism [5;51], sensitivity was $29.5 \%$ [51], similar to our data. The LANSS may be most sensitive in patient cohorts who demonstrate mainly positive sensory gains rather than negative sensory signs. Specifically, only $11 \%$ of our definite NeP patients demonstrated allodynia, and a positive response regarding autonomic dysfunction was reported in only $15.6 \%$ of patients compared to $90 \%$ and $55 \%$ respectively in the LANSS validation study [9]. Similar observations to ours have been reported in patients with low back-related leg pain [61]. In the original LANSS studies [9], a significant association between allodynia and hyperalgesia was found, however in our cohort, hyposensitivity seemed to be more frequent than hypersensitivity, consistent with findings from previous studies [57;61]. The specificity of LANSS was 
comparable to previous studies $[9 ; 51 ; 58 ; 65 ; 68]$, indicating its usefulness in negating $\mathrm{NeP}$ components in patients with chronic musculoskeletal pain.

The PD-Q demonstrated a sensitivity of $64 \%$ in identifying NeP, which is similar to the sensitivity $(67 \%)$ reported in a Spanish patient cohort of 221 patients with NeP (32\%), nociceptive (32\%) and mixed pain (36\%) [24]. However, our calculated sensitivity might not truly reflect the identification of NeP: as a self-administered tool, the PD-Q is open to individual interpretation. Eight of our patients failed to identify their main area of pain on the PD-Q body chart and 45 patients indicated additional, multiple pain areas (78\% related to LBP and leg pain). Thus, it is possible that in $35 \%$ of our patient cohort, the responses given in PD-Q might have related to areas additional to the main pain area. Out of these 53 patients, 36 were clinically classified as definite and probable NeP patients and PD-Q identified 24 of these patients. Our findings support the statement that the discriminative ability of $\mathrm{NeP}$ screening tools is only reliable when applied to one specific painful area [16;53]. Out of 29 patients classified by PD-Q and the clinical assessment as having NeP, there were inconsistent responses to the common questions between LANSS and PD-Q in 25\% of cases. If responses to these questions had been similar in the PD-Q as in LANSS, the sensitivity of PD-Q would have reduced to $48.9 \%$. Providing specific instructions on how to complete the PD-Q therefore appears important.

With a lack of published studies documenting clinical diagnostic accuracy and reliability of the English version of PD-Q in patients with peripheral $\mathrm{NeP}[1 ; 16]$, the validity of PD-Q for use in screening patients with neck/arm pain may be questionable. It is unclear if the lowered sensitivity of PD-Q in our study might relate 
to variations in patient cohorts, as specific patient characteristics were not reported in the original validation study [30].

Fundamental differences also exist between LANSS and PD-Q design, i.e. the timeframe of the presenting pain, the number and type of items included, the phrasing of the questions and the scoring method. Whilst LANSS uses fixed scores for each question, sensory descriptor items are weighted in PD-Q, thus responses could be vulnerable to psychological factors such as hypervigilance and catastrophizing, as demonstrated in another study [40], potentially contributing to an overall higher score.

The differences in design of LANSS and PD-Q tools, together with the low level of agreement between instruments, would not support the interchangeable use of these questionnaires. Furthermore, the discriminative ability of these tools in identifying $\mathrm{NeP}$ components in patients with neck/upper limb pain of mixed aetiology is questionable. Our findings strongly support the notion that results of NeP screening tools should always be used in conjunction with comprehensive clinical assessment of the patient and should not replace clinical judgement [22;34;37].

Our study findings should be interpreted in light of various limitations. As patients were suspected of having a nerve lesion, there may be an element of selection bias against patients with no nerve lesion, although the presence of a nerve lesion does not necessarily equate with NeP. While sensory testing of thermal sensibility was not performed in this study, consistent with previous methodology [39;66], this might have increased the number of patients demonstrating sensory alterations and probable or definite NeP. Blinding of the investigator and an assessment by a second clinician 
would have enhanced the validity of our findings, however this was not possible for reasons previously outlined in our methods. These issues reflect the real world where tensions between what might be robust pure research collide with pragmatic design. While investigation of the reliability of the NeuPSIG grading system was not the primary aim of our study, this should be addressed in a future study.

The NeuPSIG's proposed grading system for NeP could readily be applied to a cohort of patients with neck/upper limb pain. This classification approach might not be feasible in primary care settings for patients with complex pain presentations due to the time and specific expertise required for classification. The diagnostic accuracy of LANSS and PD-Q for the identification of NeP in patients with neck/upper limb pain appears limited. 


\section{Acknowledgement}

This study was supported by the National Health and Medical Research Council

(Grant 425560), Arthritis Australia (Victorian Ladies' Bowls Association Grant) and

the Physiotherapy Research Foundation (seeding grant). The authors thank Dr Anne J

Smith for her statistical advice and all participants in this research. The authors

declare no conflicts of interest. 


\section{Reference List}

[1] Attal N. Screening tools for neuropathic pain: Are they adaptable in different languages and cultures? Pain Med 2010;11:985-986.

[2] Backonja MM. Defining neuropathic pain. Anesth Analg 2003;97.

[3] Baron R, Binder A. How neuropathic is sciatica? The mixed pain concept. Orthopäde 2004;33:568-575.

[4] Baron R, Binder A, Wasner G. Neuropathic pain: diagnosis, pathophysiological mechanisms, and treatment. Lancet Neurol 2010;9:807-819.

[5] Baron R, Tölle TR. Assessment and diagnosis of neuropathic pain. Curr Opin Support Palliat Care 2008;2:1-8.

[6] Behrman M, Linder R, Assadi AH, Stacey BR, Backonja M-M. Classification of patients with pain based on neuropathic pain symptoms: Comparison of an artificial neural network against an established scoring system. Eur J Pain 2007;11:370-376.

[7] Beith ID, Kemp A, Kenyon J, Prout M, Chestnut TJ. Identifying neuropathic back and leg pain: a cross-sectional study. Pain 2011;152:1511-1516.

[8] Bennett GJ. Can we distinguish between inflammatory and neuropathic pain? Pain Res Manag 2006;11:11-15.

[9] Bennett M. The LANSS pain scale: The Leeds Assessment of Neuropathic Symptoms and Signs. Pain 2001;92:147-157.

[10] Bennett MI, Attal N, Backonja MM, Baron R, Bouhassira D, Freynhagen R, Scholz J, Tölle TR, Wittchen H-U, Jensen TS. Using screening tools to identify neuropathic pain. Pain 2007;127:199-203.

[11] Bennett MI, Blair HS, Torrance N, Potter J. The S-LANSS score for identifying pain of predominantly neuropathic origin: validation for use in clinical and postal research. J Pain 2005;6:149-158.

[12] Bennett MI, Smith BH, Torrance N, Lee AJ. Can pain can be more or less neuropathic? Comparison of symptom assessment tools with ratings of certainty by clinicians. Pain 2006;122:289-294.

[13] Berger A, Dukes EM, Oster G. Clinical characteristics and economic costs of patients with painful neuropathic disorders. J Pain 2004;5:143-149.

[14] Bindman AB, Forrest CB, Britt H, Crampton P, Majeed A. Diagnostic scope of and exposure to primary care physicians in Australia, New Zealand, and the 
United States: Cross sectional analysis of results from three national surveys. Br Med J 2007;334:1261.

[15] Bono CM, Ghiselli G, Gilbert TJ, Kreiner DS, Reitman C, Summers JT, Baisden JL, Easa J, Fernand R, Lamer T, Matz PG, Mazanec DJ, Resnick DK, Shaffer WO, Sharma AK, Timmons RB, Toton JF. An evidence-based clinical guideline for the diagnosis and treatment of cervical radiculopathy from degenerative disorders. Spine J 2011;11:64-72.

[16] Bouhassira D, Attal N. Diagnosis and assessment of neuropathic pain: The saga of clinical tools. Pain 2011;152:S74-S83.

[17] Bouhassira D, Attal N, Alchaar H, Boureau F, Brochet B, Bruxelle J, Cunin G, Fermanian J, Ginies P, Grun-Overdyking A, Jafari-Schluep H, Lantéri-Minet M, Laurent B, Mick G, Serrie A, Valade D, Vicaut E. Comparison of pain syndromes associated with nervous or somatic lesions and development of a new neuropathic pain diagnostic questionnaire (DN4). Pain 2005;114:29-36.

[18] Bouhassira D, Lantéri-Minet M, Attal N, Laurent B, Touboul C. Prevalence of chronic pain with neuropathic characteristics in the general population. Pain 2008; 136:380-387.

[19] Campbell JL. Provision of primary care in different countries. Br Med J 2007;334:1230.

[20] Chan AW, MacFarlane IA, Bowsher D, Campbell JA. Weighted needle pinprick sensory thresholds: a simple test of sensory function in diabetic peripheral neuropathy. J Neurol Neurosurg Psychiatry 1992;55:56-59.

[21] Collins. English Dictionary: HarperCollins Publishers, 1991.

[22] Cruccu G, Sommer C, Anand P, Attal N, Baron R, Garcia-Larrea L, Haanpää M, Jensen TS, Serra J, Treede RD. EFNS guidelines on neuropathic pain assessments: revised 2009. Eur J Neurol 2010;17:1010-1018.

[23] Dalton PA, Jull GA. The distribution and characteristics of neck-arm pain in patients with and without a neurological deficit. Aust J Physiother 1989;35:38.

[24] De Andrés J, Pérez-Cajaraville J, Lopez-Alarcón MD, López-Millán JM, Margarit C, Rodrigo-Royo MD, Franco-Gay ML, Abejón D, Ruiz MA, LópezGomez V, Pérez M. Cultural adaptation and validation of the painDETECT scale into Spanish. Clin J Pain 2012;28:243-253. 
[25] Doth AH, Hansson PT, Jensen MP, Taylor RS. The burden of neuropathic pain: A systematic review and meta-analysis of health utilities. Pain 2010;149:338344.

[26] Dudgeon BJ, Ehde DM, Cardenas DD, Engel JM, Hoffman AJ, Jensen MP. Describing pain with physical disability: Narrative interviews and the McGill Pain Questionnaire. Arch Phys Med Rehabil 2005;86:109-115.

[27] Dworkin RH, Jensen MP, Gammaitoni AR, Olaleye DO, Galer BS. Symptom profiles differ in patients with neuropathic versus non-neuropathic pain. J Pain 2007;8:118-126.

[28] Dworkin RH, Turk DC, Revicki DA, Harding G, Coyne KS, Peirce-Sandner S, Bhagwat D, Everton D, Burke LB, Cowan P, Farrar JT, Hertz S, Max MB, Rappaport BA, Melzack R. Development and initial validation of an expanded and revised version of the Short-form McGill Pain Questionnaire (SF-MPQ2). Pain 2009;144:35-42.

[29] Edgar D, Zorzi LM, Wand BM, Brockman N, Griggs C, Clifford M, Wood F. Prevention of neural hypersensitivity after acute upper limb burns:

Development and pilot of a cortical training protocol. Burns 2011;37:698-706.

[30] Freynhagen R, Baron R, Gockel U, Tölle TR. painDETECT: A new screening questionnaire to identify neuropathic components in patients with back pain. Curr Med Res Opin 2006;22:1911-1920.

[31] Geber C, Baumgärtner U, Schwab R, Müller H, Stoeter P, Dieterich M, Sommer C, Birklein F, Treede RD. Revised definition of neuropathic pain and its grading system: An open case series illustrating its use in clinical practice. Am J Med 2009;122:S3-S12.

[32] Guastella V, Mick G, Soriano C, Vallet L, Escande G, Dubray C, Eschalier A. A prospective study of neuropathic pain induced by thoracotomy: Incidence, clinical description, and diagnosis. Pain 2011;152:74-81.

[33] Gwilym SE, Keltner JR, Warnaby CE, Carr AJ, Chizh B, Chessell I, Tracey I. Psychophysical and functional imaging evidence supporting the presence of central sensitization in a cohort of osteoarthritis patients. Arthritis Care Res 2009;61:1226-1234.

[34] Haanpää M, Attal N, Backonja M, Baron R, Bennett M, Bouhassira D, Cruccu G, Hansson P, Haythornthwaite JA, Iannetti GD, Jensen TS, Kauppila T, Nurmikko TJ, Rice ASC, Rowbotham M, Serra J, Sommer C, Smith BH, 
Treede R-D. NeuPSIG guidelines on neuropathic pain assessment. Pain 2011;152:14-27.

[35] Haanpää ML, Backonja MM, Bennett MI, Bouhassira D, Cruccu G, Hansson PT, Jensen TS, Kauppila T, Rice ASC, Smith BH, Treede RD, Baron R. Assessment of neuropathic pain in primary care. Am J Med 2009;122:S13S21.

[36] Hallström H, Norrbrink C. Screening tools for neuropathic pain: Can they be of use in individuals with spinal cord injury? Pain 2011;152:772-779.

[37] Hansson P, Haanpää M. Diagnostic work-up of neuropathic pain: Computing, using questionnaires or examining the patient? Eur J Pain 2007;11:367-369.

[38] Harden N, Cohen M. Unmet needs in the management of neuropathic pain. J Pain Symptom Manage 2003;25:S12-S17.

[39] Haroun OMO, Hietaharju A, Bizuneh E, Tesfaye F, Brandsma JW, Haanpää M, Rice ASC, Lockwood DNJ. Investigation of neuropathic pain in treated leprosy patients in Ethiopia: A cross-sectional study. Pain 2012;153:16201624.

[40] Hochman JR, Gagliese L, Davis AM, Hawker GA. Neuropathic pain symptoms in a community knee OA cohort. Osteoarthritis Cartilage 2011;19:647-654.

[41] Jensen TS, Baron R. Translation of symptoms and signs into mechanisms in neuropathic pain. Pain 2003;102:1-8.

[42] Jensen TS, Baron R, Haanpää M, Kalso E, Loeser JD, Rice ASC, Treede R-D. A new definition of neuropathic pain. Pain 2011;152:2204-2205

[43] Konopka K-H, Harbers M, Houghton A, Kortekaas R, van Vliet A, Timmerman W, den Boer JA, Struys MMRF, van Wijhe M. Somatosensory profiles but not numbers of somatosensory abnormalities of neuropathic pain patients correspond with neuropathic pain grading. PLoS ONE 2012;7:e43526.

[44] Krause SJ, Backonja M. Development of a neuropathic pain questionnaire. Clin J Pain 2003;9:306-314.

[45] Krumova EK, Westermann A, Maier C. Quantitative sensory testing: a diagnostic tool for painful neuropathy. Future Neurology 2010;5:721-733.

[46] Landis JR, Koch GG. The measurement of observer agreement for categorical data. Biometrics 1977;33:159-174. 
[47] Lehto IJ, Tertti MO, Komu ME, Paajanen HEK, Tuominen J, Kormano MJ. Agerelated MRI changes at $0.1 \mathrm{~T}$ in cervical discs in asymptomatic subjects. Neuroradiology 1994;36:49-53.

[48] Marchettini P. The burning case of neuropathic pain wording. Pain 2005;114:313-314.

[49] Marchettini P, Lacerenza M, Mauri E, Marangoni C. Painful peripheral neuropathies. Curr Neuropharmacol 2006;4:175-181.

[50] Matsumoto M, Fujimura Y, Suzuki N, Nishi Y, Nakamura M, Yabe Y, Shiga H. MRI of cervical intervertebral discs in asymptomatic subjects. J Bone Joint Surg Am 1998;80:19.

[51] Mercadante S, Gebbia V, David F, Aielli F, Verna L, Casuccio A, Porzio G, Mangione S, Ferrera P. Tools for identifying cancer pain of predominantly neuropathic origin and opioid responsiveness in cancer patients. J Pain 2009;10:594-600.

[52] Merskey H, Bogduk N. Classification of chronic pain. Seattle: IASP Press 1994.

[53] Mulvey MR, McBeth J. Comment on: "Self-reported somatosensory symptoms of neuropathic pain in fibromyalgia and chronic widespread pain correlated with tender point count and pressure-pain thresholds" by Amris et al. [Pain;151:664-669]. Pain 2011;152:1684-1685.

[54] Pérez C, Gálvez R, Insausti J, Bennett M, Díaz S, Rejas J. 931 Linguistic validation into spanish of the LANSS (Leeds Assessment of Neuropathic Symptoms and Signs) scale. Eur J Pain 2006;10:S241-S241.

[55] Pewsner D, Battaglia M, Minder C, Marx A, Bucher HC, Egger M. Information in practice: Ruling a diagnosis in or out with "SpPIn" and "SnNOut": a note of caution. Br Med J 2004;329:209-213.

[56] Portney LG, Watkins MP. Foundations of clinical research - Applications to practice. New Jersey: Pearson Education, Inc., 2009.

[57] Rasmussen Pv, Sindrup HS, Jensen TS, Bach FW. Symptoms and signs in patients with suspected neuropathic pain. Pain 2004;110:461-469.

[58] Rejas J, Pérez C, Gálvez R, Insausti J, Bennet M, Díaz S. Validity of the LANSS scale for differential diagnosis of patients with neuropathic or mixed pain versus non-neuropathic pain. Eur J Pain 2006;10:S241-S241.

[59] Roth D, Mukai A, Thomas P, Hudgins TH, Alleva JT. Cervical radiculopathy. Dis Mon 2009;55:737-756. 
[60] Saldaña MT, Navarro A, Pérez C, Masramón X, Rejas J. A cost-consequences analysis of the effect of pregabalin in the treatment of painful radiculopathy under medical practice conditions in primary care settings. Pain Pract 2010;10:31-41.

[61] Scholz J, Mannion RJ, Hord DE, Griffin RS, Rawal B, Zheng H, Scoffings D, Philips A, Guo J, Laing RJC, Abdi S, Decosterd I, Woolf CJ. A novel tool for the assessment of pain: Validation in low back pain. PLoS Med 2009;6:1-16.

[62] Tampin B, Briffa NK, Slater H. Self-reported sensory descriptors are associated with quantitative sensory testing parameters in patients with cervical radiculopathy, but not in patients with fibromyalgia. Eur J Pain 2013;17:621633.

[63] Tanaka Y, Kokubun S, Sato T, Ozawa H. Cervical roots as origin of pain in the neck and scapular regions. Spine 2006;31:E568-E573.

[64] Treede R-D, Jensen TS, Campbell JN, Cruccu G, Dostrovsky JO, Griffin JW, Hansson P, Hughes R, Numikko T, Serra J. Neuropathic pain. Redifinition and a grading system for clinical and research purposes. Neurology 2008;70:16301635 .

[65] Unal-Cevik I, Sarioglu-Ay S, Evcik D. A comparison of the DN4 and LANSS questionnaires in the assessment of neuropathic pain: Validity and reliability of the Turkish version of DN4. J Pain 2010;11:1129-1135.

[66] Weingarten TN, Watson JC, Hooten WM, Wollan PC, Melton III LJ, Locketz AJ, Wong GY, Yawn BP. Validation of the S-LANSS in the community setting. Pain 2007;132:189-194.

[67] Wilkie DJ, Molokie R, Boyd-Seal D, Suarez ML, Ok Kim Y, Zong S, Wittert H, Zhao Z, Saunthararajah Y, Wang ZJ. Patient-reported outcomes: Descriptors of nociceptive and neuropathic pain and barriers to effective pain management in adult outpatients iwth sickle cell disease. J Natl Med Assoc 2010;102:1827.

[68] Yucel A, Senocak M, Kocasoy Orhan E, Cimen A, Ertas M. Results of the Leeds Assessment of Neuropathic Symptoms and Signs pain scale in Turkey: A validation study. J Pain 2004;5:427-432. 


\section{Table 1}

Characteristics of patients $(\mathrm{N}=152)$ with neck/upper limb pain classified according to the NeuPSIG grading system as no, possible, probable or definite neuropathic pain $(\mathrm{NeP})$.

\begin{tabular}{|c|c|c|c|c|}
\hline & No NeP & Possible NeP & Probable NeP & Definite $\mathrm{NeP}$ \\
\hline $\mathrm{N}$ & 15 & 27 & 65 & 45 \\
\hline Age (years) $)^{\mathrm{a}}$ & $58.0(14.4)$ & $51.2(10.0)$ & $51.1(12.0)$ & $52.6(11.0)$ \\
\hline Gender (women/men) & $5 / 10$ & $14 / 13$ & $33 / 32$ & $20 / 25$ \\
\hline \multirow[t]{2}{*}{ Symptoms duration (months) ${ }^{\mathrm{b}}$} & 18.0 & 9.0 & 17.0 & 10.0 \\
\hline & $(3.0-240.0)$ & $(2.0-126.0)$ & $(1.5-228.0)$ & $(1.0-204.0)$ \\
\hline \multirow[t]{2}{*}{ Pain now (NRS $0-10)^{\mathrm{a}}$} & $3.6(2.4)$ & $4.5(2.3)$ & $4.8(2.3)$ & $4.7(2.2)$ \\
\hline & & & $(\mathrm{n}=64)$ & \\
\hline Maximal pain intensity during last 4 weeks & $6.7(2.6)$ & $7.1(2.5)$ & $7.5(2.3)$ & $7.8(1.9)$ \\
\hline$(\mathrm{NRS} 0-10)^{\mathrm{a}}$ & & & $(n=63)$ & \\
\hline Average pain intensity during last 4 weeks & $5.1(2.8)$ & $6.0(2.4)$ & $5.9(2.0)$ & $6.0(1.9)$ \\
\hline$(\mathrm{NRS} 0-10)^{\mathrm{a}}$ & & & $(\mathrm{n}=63)$ & \\
\hline $\mathrm{N}$ on antidepressants, anticonvulsants or opioids & $2(13.3 \%)$ & $6^{\mathrm{c}}(22.2 \%)$ & $21^{\mathrm{d}}(32.3 \%)$ & $16^{\mathrm{e}}(35.5 \%)$ \\
\hline $\mathrm{N}$ on analgesics (paracetamol, NSAIDS) & $2(13.3 \%)$ & $8(29.6 \%)$ & $15(23.1 \%)$ & $17(37.8 \%)$ \\
\hline
\end{tabular}

\footnotetext{
${ }^{\mathrm{a}}$ Mean $\pm \mathrm{SD} ;{ }^{\mathrm{b}}$ Median and range; ${ }^{\mathrm{c}} \mathrm{n}=1$ also on analgesic, ${ }^{\mathrm{d}} \mathrm{n}=10$ also on analgesic, ${ }^{\mathrm{e}} \mathrm{n}=7$ also on analgesic.
} 


\section{Table 2}

Pain diagnoses/pain presentations ${ }^{\mathrm{a}}$ and neuropathic pain $(\mathrm{NeP})$ classifications in patients $(\mathrm{N}=152)$ with neck/upper limb pain.

\begin{tabular}{|c|c|c|c|c|c|c|c|c|c|c|}
\hline \multirow{3}{*}{ Pain diagnoses/presentations } & \multicolumn{5}{|c|}{ Clinical classification } & \multicolumn{2}{|c|}{ LANSS } & \multicolumn{3}{|c|}{ painDETECT } \\
\hline & $\mathrm{N}$ & No & Possible & Probable & Definite & No & Yes & No & Unclear & Yes \\
\hline & & $\mathrm{NeP}$ & $\mathrm{NeP}$ & $\mathrm{NeP}$ & $\mathrm{NeP}$ & $\mathrm{NeP}$ & $\mathrm{NeP}$ & $\mathrm{NeP}$ & $\mathrm{NeP}$ & $\mathrm{NeP}$ \\
\hline $\mathrm{N}$ & 152 & 15 & 27 & 65 & 45 & 129 & 23 & 46 & 36 & 70 \\
\hline \multicolumn{11}{|l|}{ Radiculopathy } \\
\hline Cervical radiculopathy ${ }^{\mathrm{b}}$ & 33 & & & 9 & 24 & 24 & 9 & 7 & 7 & 19 \\
\hline Sensory cervical radiculopathy ${ }^{\mathrm{c}}$ & 12 & & 1 & 4 & 7 & 10 & 2 & 3 & 4 & 5 \\
\hline Motor radiculopathy ${ }^{\mathrm{d}}$ & 5 & & & 4 & 1 & 5 & & 2 & 3 & \\
\hline \multicolumn{11}{|l|}{ Radicular pain } \\
\hline $\begin{array}{l}\text { Radicular neck/arm pain with distal } \\
\text { paraesthesia in dermatomal distribution }\end{array}$ & 19 & & 4 & 11 & 4 & 16 & 3 & 2 & 5 & 12 \\
\hline Radicular neck/arm pain & 11 & & 1 & 7 & 3 & 10 & 1 & 3 & 4 & 4 \\
\hline $\begin{array}{l}\text { Radicular neck/arm pain with non dermatomal } \\
\text { distal paraesthesia }\end{array}$ & 8 & & 2 & 5 & 1 & 6 & 2 & 1 & 2 & 5 \\
\hline Radicular pain with bilateral hand paraesthesia & 3 & & & 2 & 1 & 3 & & & 1 & 2 \\
\hline Neck pain & 13 & 5 & 4 & 3 & 1 & 13 & & 7 & 3 & 3 \\
\hline Neck pain with unilateral arm and/or hand pain & 18 & 5 & 6 & 7 & & 17 & 1 & 9 & 2 & 7 \\
\hline
\end{tabular}




\begin{tabular}{|c|c|c|c|c|c|c|c|c|c|c|}
\hline /paraesthesia & & & & & & & & & & \\
\hline $\begin{array}{l}\text { Neck pain with bilateral arm and/or hand pain } \\
\text { /paraesthesia }\end{array}$ & 14 & 4 & 3 & 7 & & 13 & 1 & 7 & 1 & 6 \\
\hline Whiplash injury related pain & 6 & & 4 & 2 & & 4 & 2 & 1 & 2 & 3 \\
\hline Cervical myelopathy & 2 & & & & 2 & 2 & & 1 & & 1 \\
\hline Carpal tunnel syndrome & 2 & & & 2 & & 2 & & 1 & & 1 \\
\hline Other & 6 & 1 & 2 & 2 & 1 & 4 & 2 & 2 & 2 & 2 \\
\hline
\end{tabular}

${ }^{a}$ As determined by clinician based on history, examination results (neurological and musculoskeletal status) and results of investigations.

${ }^{\mathrm{b}}$ Dermatomal pain/symptom distribution plus sensory dermatomal deficit plus motor impairment (either reflex absent/diminished or myotomal weakness).

${ }^{\mathrm{c}}$ Dermatomal pain/symptom distribution plus sensory dermatomal deficit, no motor impairment.

${ }^{\mathrm{d}}$ Dermatomal pain/symptom distribution plus motor impairment, no sensory dermatomal deficit. 


\section{Table 3}

Frequencies of neuropathic pain $(\mathrm{NeP})$ in patients $(\mathrm{N}=152)$ with neck/upper limb pain, using two classification categories: no $\mathrm{NeP}-\mathrm{NeP}$.

\begin{tabular}{|c|c|c|c|c|}
\hline & \multicolumn{4}{|c|}{ Clinical classification } \\
\hline & & No NeP & $\mathrm{NeP}$ & Total \\
\hline \multirow[t]{5}{*}{$\mathrm{LANSS}^{\mathrm{a}}$} & No NeP & 94 & 35 & 129 \\
\hline & $\mathrm{NeP}$ & 13 & 10 & 23 \\
\hline & Total & 107 & 45 & 152 \\
\hline & \multicolumn{4}{|c|}{ Clinical classification } \\
\hline & & No NeP & $\mathrm{NeP}$ & Total \\
\hline \multirow[t]{5}{*}{ painDETECT $^{\mathrm{b}}$} & No NeP & 66 & 16 & 82 \\
\hline & $\mathrm{NeP}$ & 41 & 29 & 70 \\
\hline & Total & 107 & 45 & 152 \\
\hline & & \multicolumn{2}{|c|}{ painDETECT } & \\
\hline & & No NeP & $\mathrm{NeP}$ & Total \\
\hline \multirow[t]{3}{*}{ LANSS $^{c}$} & No NeP & 77 & 52 & 129 \\
\hline & $\mathrm{NeP}$ & 5 & 18 & 23 \\
\hline & Total & 82 & 70 & 152 \\
\hline
\end{tabular}

${ }^{\mathrm{a}} 68.4 \%$ of agreement between clinical classification and LANSS.

${ }^{\mathrm{b}} 62.5 \%$ of agreement between clinical classification and painDETECT.

${ }^{\mathrm{c}} 62.5 \%$ of agreement between LANSS and painDETECT. 


\section{Table 4}

Accuracy of screening tools in identifying patients with neuropathic pain

\begin{tabular}{lccccccc}
\hline & \% Sensitivity & \% Specificity & PPV & NPV & LR+ & LR- & DOR \\
\hline LANSS & 22 & 88 & 0.44 & 0.31 & 1.83 & 0.89 & 2.0 \\
painDETECT & 64 & 62 & 0.42 & 0.80 & 1.68 & 0.58 & 2.9
\end{tabular}

LANSS: Leeds Assessment of Neuropathic Symptoms and Signs pain scale; PPV: Positive predictive value; NPV: Negative predictive value;

LR: Likelihood ratio; DOR: Diagnostic Odds Ratio 


\section{Table 5}

Frequency of pain descriptors with logistic regression analysis for each item descriptor

\begin{tabular}{|c|c|c|c|c|c|c|}
\hline \multirow[t]{2}{*}{ Questionnaire } & \multirow[t]{2}{*}{ Item descriptor } & \multicolumn{2}{|c|}{$\begin{array}{c}\mathrm{NeP} \\
(\mathrm{n}=45)\end{array}$} & \multicolumn{2}{|c|}{$\begin{array}{l}\text { No NeP } \\
(n=107)\end{array}$} & \multirow[b]{2}{*}{ p-value } \\
\hline & & Yes (n) & $\%$ & Yes (n) & $\%$ & \\
\hline \multirow[t]{7}{*}{ LANSS } & Pricking/tingling/pins and needles & 36 & 80 & 57 & 53.3 & 0.001 \\
\hline & Skin discoloration & 7 & 15.6 & 7 & 6.5 & 0.092 \\
\hline & Sensitivity to light touch & 7 & 15.6 & 21 & 19.6 & 0.549 \\
\hline & Sudden bursts of pain/electric shocks & 24 & 53.3 & 44 & 41.1 & 0.168 \\
\hline & Feeling of altered skin temperature/hot/burning & 26 & 57.8 & 46 & 43 & 0.095 \\
\hline & Allodynia to light touch & 5 & 11.1 & 2 & 1.9 & 0.019 \\
\hline & Altered pin-prick sensation & 36 & 80 & 42 & 39.3 & $<0.001$ \\
\hline \multirow[t]{5}{*}{ PD-Q } & Pain Pattern & & & & & 0.035 \\
\hline & Persistent pain with slight fluctuation & 10 & 22.2 & 36 & 33.6 & \\
\hline & Persistent pain with pain attacks & 23 & 51.1 & 32 & 29.9 & \\
\hline & Pain attacks without pain between them & 4 & 8.9 & 17 & 15.9 & \\
\hline & Pain attacks with pain between them & 11 & 24.4 & 29 & 27.1 & \\
\hline
\end{tabular}




$\begin{array}{lccccc}\text { Radiating pain } & 36 & 80 & 77 & 72 & 0.845 \\ \text { Burning sensation } & 26 & 57.8 & 54 & 50.5 & 0.510 \\ \text { Tingling/prickling sensation } & 37 & 82.2 & 59 & 55.1 & \mathbf{0 . 0 0 1} \\ \text { Painful light touch } & 5 & 11.1 & 21 & 19.6 & 0.198 \\ \text { Sudden pain attacks/electric shocks } & 36 & 80 & 56 & 52.3 & \mathbf{0 . 0 0 1} \\ \text { Cold or heat painful } & 7 & 15.6 & 20 & 18.7 & 0.682 \\ \text { Numbness } & 33 & 73.3 & 57 & 53.3 & \mathbf{0 . 0 2 3} \\ \text { Slight pressure painful } & 28 & 62.2 & 53 & 49.5 & 0.150\end{array}$

LANSS: Leeds Assessment of Neuropathic Symptoms and Signs pain scale; PD-Q: painDETECT; NeP: Neuropathic pain 
<smiles>CC#CC#C[Si](C)(C)C#CC</smiles> 
Fig. 1 Frequency of sensory descriptors volunteered by 152 patients with neck/upper limb pain, classified as no neuropathic pain $(\mathrm{NeP})$, possible $\mathrm{NeP}$, probable $\mathrm{NeP}$ and definite $\mathrm{NeP}$, is shown. 


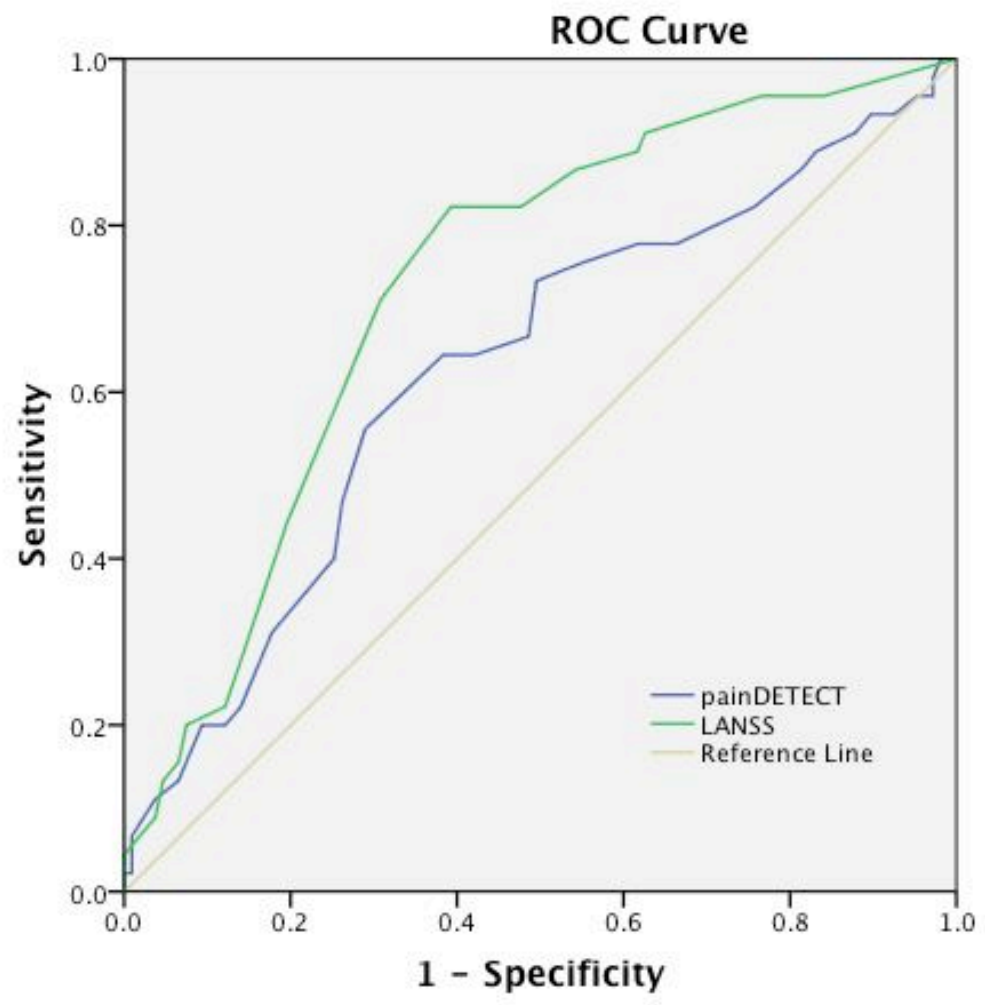

Fig. 2 ROC curve and AUC of the Leeds Assessment of Neuropathic Symptoms and Signs (LANSS) and painDETECT questionnaire (PD-Q) 